\author{
Asian Journal of \\ Medical and Biological Research \\ ISSN 2411-4472 (Print) 2412-5571 (Online) \\ www.ebupress.com/journal/ajmbr
}

\title{
Article \\ Gross and histomorphological effects of formaldehyde on brain and lungs of Swiss albino mice
}

\author{
Marya Afrin, Tanjina Amin, Md. Rabiul Karim and M. Rafiqul Islam* \\ Department of Anatomy and Histology, Faculty of Veterinary Science, Bangladesh Agricultural University, \\ Mymensingh, Bangladesh
}

*Corresponding author: Professor Dr. M. Rafiqul Islam, Department of Anatomy and Histology, Faculty of Veterinary Science, Bangladesh Agricultural University, Mymensingh-2202, Bangladesh. Phone: +8801741355282; Fax: +880-91-67431, 61510; E-mail: rafiqah77@yahoo.com

Received: 07 June 2016/Accepted: 21 June 2016/ Published: 30 June 2016

\begin{abstract}
Formaldehyde (FA) is toxic over a range of doses and of particular concern to anatomists and medical students on laboratory use. FA induces several characteristics of neurotoxicity in addition to systemic effects. Therefore, to know the toxic effects of FA on brain and lungs, mice were collected from international center for diarrheal disease research. They were divided into four groups i.e. control, inhalation, oral and intraperitoneal. The inhalation, oral and intraperitoneal exposure groups further divided into three subgroups which were subjected to exposure of FA daily for 30 days in case of inhalation and oral groups and 10 days in intraperitoneal group for acute toxic effects. Morphological study showed gross abnormalities i.e. congestion on lungs. But no gross abnormal features observed on brain. In $5 \mathrm{ppm}$ treated inhaled group, lungs tissue revealed hemorrhages. In the inhaled groups, brain tissue showed degenerating neurons with either pyknotic or karyorrhectic nuclei are gradually increased in highest concentration group. These data supports the view that FA has adverse effects on the morphology of brain and lungs.
\end{abstract}

Keywords: formaldehyde; congestion; pyknosis; brain; lungs; mice

\section{Introduction}

Formaldehyde (FA) is a colorless gas which has pungent odor and causes irritation to the mucous membrane of eye, nose and throat (Nelson et al., 1986). As it is a volatile gas in room temperature, it has the chance to cause harmful effect in certain doses (Songur et al., 2003). Nowadays it is the most frequently used organic carbon compound in day to day life. Although it was introduced as fixative and embalming fluid, but now it is using from indoor house environment as like aspainting material, cooking emission, fabrics, to all occupational environments such as hospitals, wood based furniture, paper, textile etc. Both house environment and occupational environment working as an exposure factor for human but the most alarming exposure factor is the use of FA in the form of formalin i.e. 37\% FA w/v solution on a wide range of products from fruits to fish to vegetables. In Bangladesh in addition to use of FA as preservative in feedstuffs, FA also occurs naturally in the environment as a result of several biochemical pathways and is a widely produced industrial chemical. Human are exposing to FA from both direct (ingestion) and environmental sources (Gurel et al., 2005). From the foregoing, one can observe that nearly all humans, including susceptible children, may be affected by FA exposure. FA is also an important public health problem, because cigarette smoke also contains FA (Tox, 2002). FA exposure has the toxic effects on respiratory system and nervous system (Cogliano et al., 2004; Collins and Lineker, 2004; Fujimaki et al., 2004). It is considered as one of the major components responsible for sick building syndrome (Nakazawa et al., 2005). Major target system of FA is respiratory system, because after inhalation it is stored as higher volume than other organ (Cui et al., 1996). It has also effect on brain that has been observed in experimental animals after repeated inhalation or oral administration (Malek et al., 2003; 
Pitten et al., 2000). The present study investigated the cellular toxicity associated with FA intoxication on the brain and lungs of mice.

\section{Materials and Methods}

\subsection{Study area and time frame}

The study was conducted in the Department of Anatomy and Histology, Faculty of Veterinary Science, Bangladesh Agricultural University, Mymensingh during the period from July, 2014 to June, 2015.

\subsection{Experimental animal}

The experimental Swiss albino mice aged 100-120 days and with a mean body weight of $30 \pm 7 \mathrm{~g}$ (male) and $25 \pm 5 \mathrm{~g}$ (female) were collected from International Center for Diarrheal Disease Research (icddr'b), Mohakhali, Dhaka having apparently good health and devoid of any external deformities certified by the registered veterinarian from icddr'b. The mice, separated according to gender, were kept in groups and housed in cages $(2 \times 1$ sq. ft) in a galvanized iron sheet roof with a brick build floor raised above the ground level littered with saw dust ( 2 inches thickness). The mice were fed with feed and water ad libitum. All animals were treated in accordance with the "Guideline for the Care and Use of Laboratory Animals" prepared by National Academy of Sciences and published by National Institute of Health (1985).

\subsection{Research design}

For the experimental purpose the mice of both sexes ( 3 female and 2 male in each group) were randomly divided into four groups like; control, inhalation, oral and intraperitoneal groups. In control group (group A) total of 5 mice were taken. Inhalation groups further divided into three groups (groups B to D) of 2 males and 3 females in each and exposed to $1.0 \mathrm{ppm}$ (group B), $2.5 \mathrm{ppm}$ (group C) and $5.0 \mathrm{ppm}$ (group D) FA vapor once for two hours for 30 days. The FA concentrations used were based on the fact that such concentrations could also appear in the human work place (Kilburn, 1994). The exposure took place in a pan $(40 \times 30 \mathrm{~cm})$ and the roof was covered with aluminum foil paper and provided with small holes to allow fresh air exchange. To generate and maintain the concentrations in the pan during the inhalation session, aqueous FA solutions of different concentrations $(0.5 \%$ for group B, $1 \%$ for group C and $2.5 \%$ for group D) were prepared using a stock FA powder (Merck, Darmstadt, Germany) and added in volume between 5-8 $\mathrm{ml}$ three to four times in an hour by means of a pipette into a flat dish which was located in the center of the bottom of the pan. At the end of exposure, the mice were returned to the cages and kept there with free access to food and water. Mice of oral group were divided into three sub-groups and exposed to $5.0 \mathrm{mg} / \mathrm{kg}$ (group B), $7.0 \mathrm{mg} / \mathrm{kg}$ (group C) and 10.0 $\mathrm{mg} / \mathrm{kg}$ body weight (group D) FA once daily for 30 days. Like inhalation and ingestion groups the mice of intraperitoneal groups were randomly divided into three sub-groups and injected to $5.0 \mathrm{mg} / \mathrm{kg}$ (group B), 7.0 $\mathrm{mg} / \mathrm{kg}$ (group C) and $10.0 \mathrm{mg} / \mathrm{kg}$ body weight (group D) FA intraperitoneally once daily for 10 days.

\subsection{Gross and histomorphological investigation}

The FA exposed and control mice (five in each group) were sacrificed by doing anesthesia with chloroform. Immediately after killing, the samples (brain and lungs) were dissected out carefully and examined by naked eye for any gross changes. The photo of gross morphological changes on brains and lungs were taken. For histomorphological examination, brains and lungs were fixed by both immersion fixation (10\% formaldehyde) and perfusion fixation (4\% paraformaldehyde) method and processed for light microscopy (Bancroft and Gamble, 2002). Haematoxyl in and Eosin stain was used to stain the tissue for preparing permanent slide. Olympus BX 51 photographic light microscope was used for taking photographs of slides.

\section{Results}

For proper comprehension of this study, the results were summarized according to the dose dependent exposure to FA into the following:

\subsection{Gross changes}

The gross morphological changes in control group (Figure 1A, 2A and $3 \mathrm{~A}$ ) revealed no visible lesions in brain of mice. The morphological appearance of the brain of $1 \mathrm{ppm}$ (Figure 1B), $2.5 \mathrm{ppm}$ (Figure 1C) and $5 \mathrm{ppm}$ (Figure 1D) inhalation groups revealed normal architechture. In oral (Figure 2B-D) and intraperitoneal groups (Figure 3B-D), there were lack of gross abnormalities observed in brain of the mice exposed to $5 \mathrm{mg} / \mathrm{kg}(\mathrm{B}), 7.5$ $\mathrm{mg} / \mathrm{kg}(\mathrm{C})$ and $10 \mathrm{mg} / \mathrm{kg}(\mathrm{D}) \mathrm{FA}$. 
In lungs of control group, there were no gross changes observed (Figure 4A, 5A and 6A). But in 5 ppm treated inhalation group, the lungs were congested (Figure 4D). Again the gross morphological changes in oral (Figure 5B-D) and intraperitoneal (Figure 6B-D) groups were lack of abnormalities observed in lungs of the mice exposed to $5 \mathrm{mg} / \mathrm{kg}(\mathrm{B}), 7.5 \mathrm{mg} / \mathrm{kg}(\mathrm{C})$ and $10 \mathrm{mg} / \mathrm{kg}$ (D) FA.
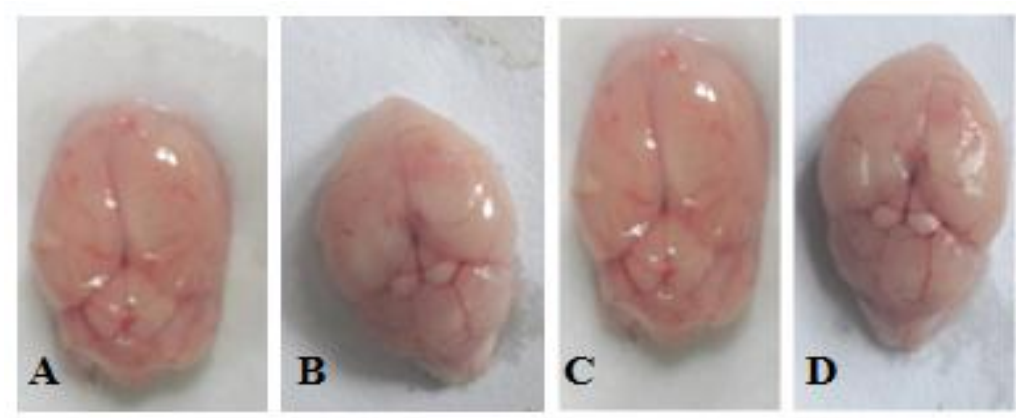

Figure 1. Gross study of brain of control (A) and inhaled grouped (B-D) mice. Normal gross morphology of lungsshowed in control (A), 1ppm(B), 2.5ppm (C) and 5ppm (D) treated inhalation group mice.
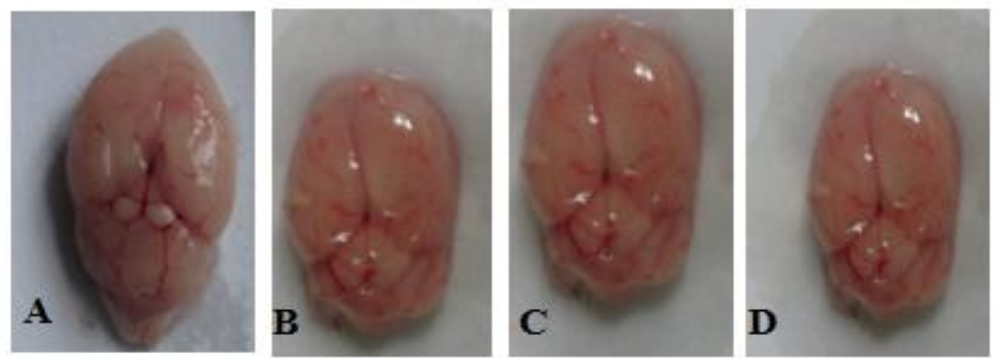

Figure 2. Gross study of brain of control (A) and oral grouped (B-D) mice. No changes observed in control (A), 5mg/kg (B), 7.5mg/kg (C) and $10 \mathrm{mg} / \mathrm{kg}$ (D) treated oral group mice.
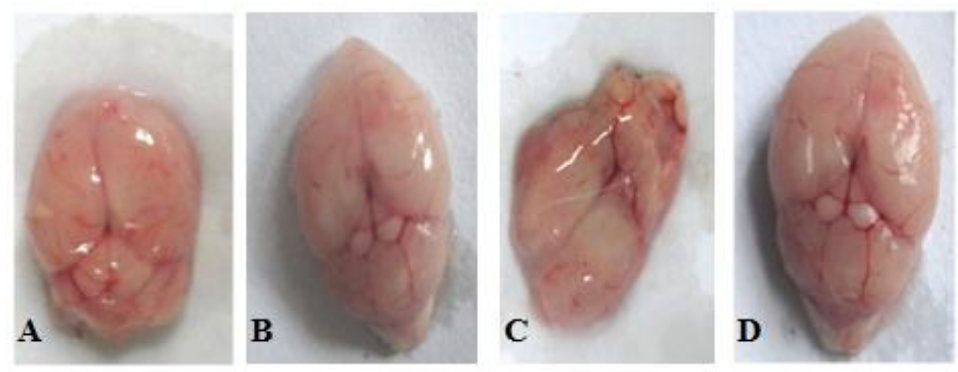

Figure 3. Gross study of brain of control (A) and intraperitoneal grouped (B-D) mice. No changes observed in control (A), 5mg/kg (B), 7.5mg/kg (C) and $10 \mathrm{mg} / \mathrm{kg}$ (D) treated intraperitoneal group mice.
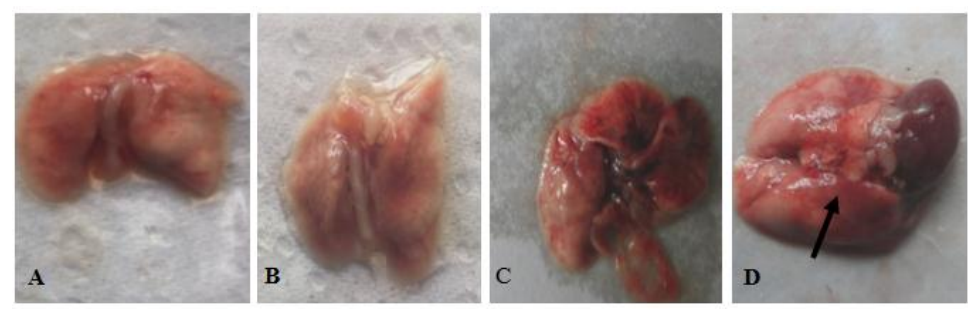

Figure 4. Gross study of lungs of control (A) and inhalation grouped (B-D) mice. Normal gross morphology of lungs showed in control (A), 1ppm (B), 2.5ppm (C) treated inhalation group mice.5ppm (D)treated inhalation group showed congestion on the lungs surface. 

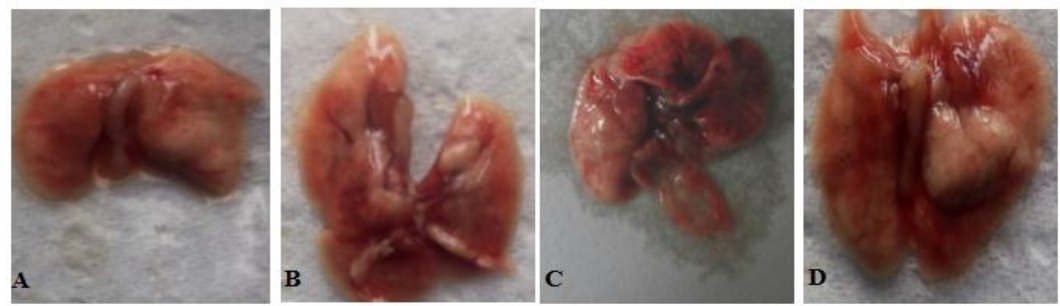

Figure 5. Gross study of lungs of control (A) and oral grouped (B-D) mice. No changes observed in control (A), 5mg/kg (B), 7.5mg/kg (C) and $10 \mathrm{mg} / \mathrm{kg}(\mathrm{D})$ treated oral group mice.
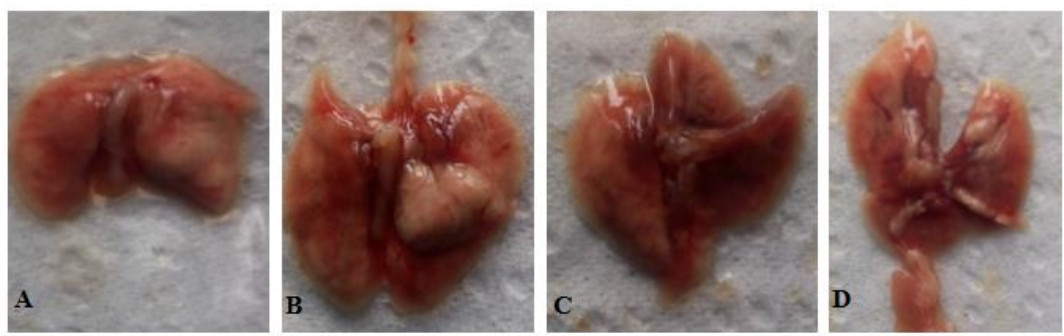

Figure 6. Gross study of lungs of control (A) and intraperitoneal grouped (B-D) mice. No changes observed in control (A), 5mg/kg (B), 7.5mg/kg (C) and $10 \mathrm{mg} / \mathrm{kg}$ (D) treated intraperitoneal group mice.

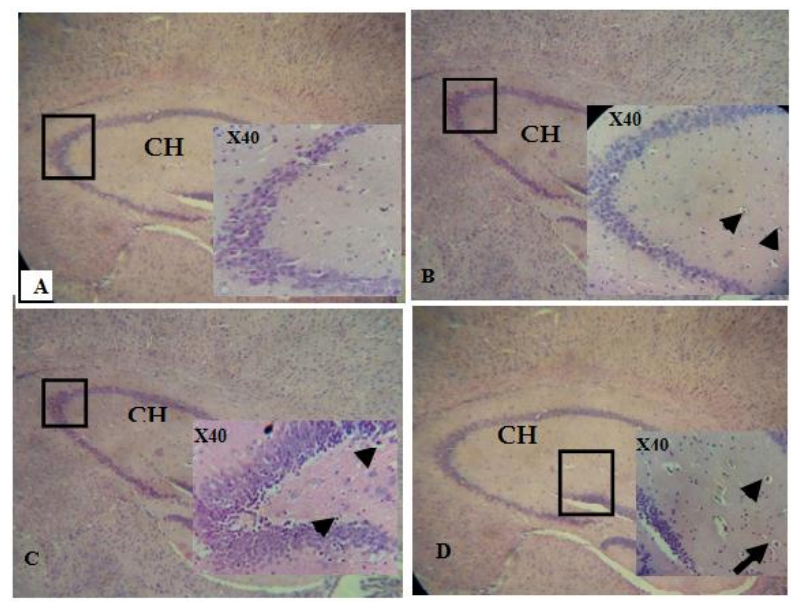

Figure 7. (A-D) Histological features in brain (cerebral hippocampus area) of control and inhaled grouped mice. Control (A) showing normal architecture of neuron (cerebral hippocampus area). B, C showing shrunken neurons with pyknotic (arrow heads) nuclei and D showing shrunken neurons with pyknotic (arrow heads) and karyorrhectic (long arrow) nuclei in $\mathrm{H}$ and $\mathrm{E}$ stain $(\mathrm{X10}) . \mathrm{CH}=\mathrm{Cerebral}$ hippocampus
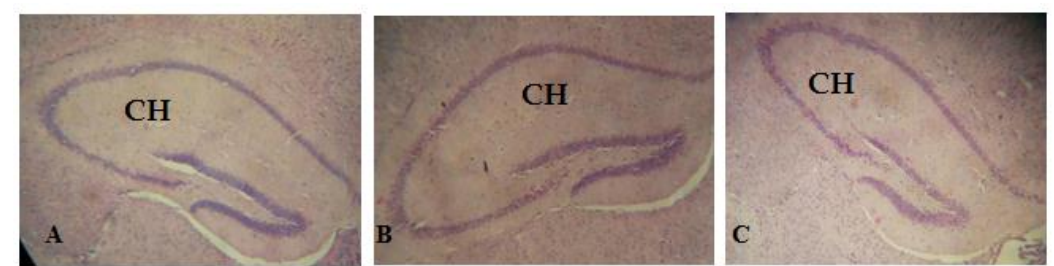

Figure 8. (A-C) Histological features in brain (cerebral hippocampus area) of control, oral and intraperitoneal grouped mice. No changes observed in control (A), $10 \mathrm{mg} / \mathrm{kg}$ treated oral (B) and 10 $\mathrm{mg} / \mathrm{kg}$ treated intraperitoneal group $(\mathrm{C})$ mice in $\mathrm{H}$ and $\mathrm{E}$ stain $(\mathrm{X10}) . \mathrm{CH}=$ Cerebral hippocampus area 

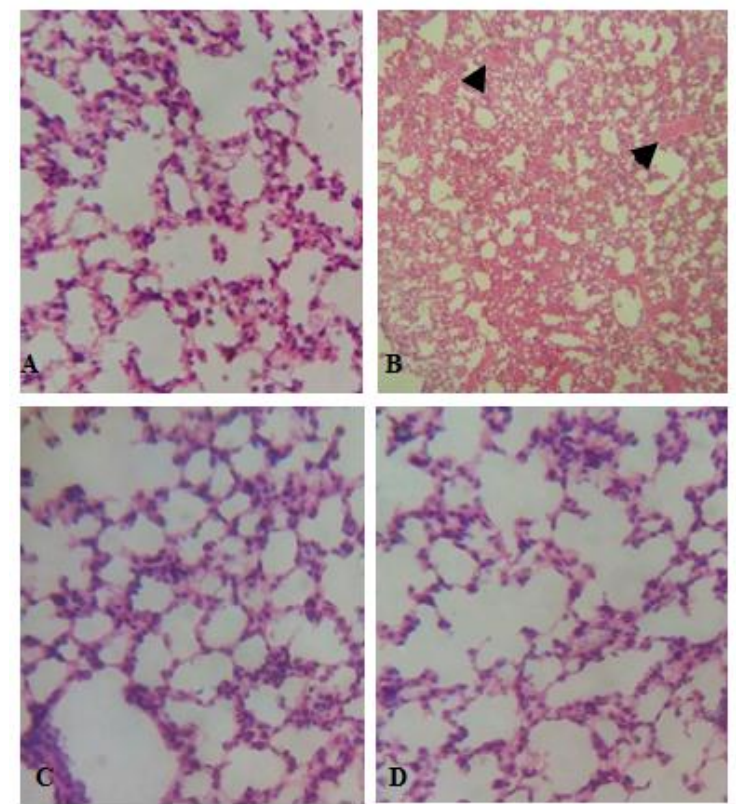

Figure 9. (A-D) Histological features in lungs of control, inhaled, oral and intraperitoneal grouped mice. $A$ is the representative figure of control group. $B$ is the representative figure of $5 \mathrm{ppm}$ treated inhaled group showing hemorrhages (arrow head). $C$ is the representative figure of $10 \mathrm{mg} / \mathrm{kg}$ treated oral group and $D$ is the representative figure of $10 \mathrm{mg} / \mathrm{kg}$ treated intraperitoneal group showing normal architecture in $\mathrm{H}$ and $\mathrm{E}$ stain (X40).

\subsection{Histomorphological changes}

\subsubsection{Brain}

Brain of control group (Figures 7A and 8A) revealed no morphological alteration. 1 ppm (Figure 7B) and 2.5 ppm (Figure 7C) treated inhalation exposure groups mice showed shrunken neurons with pyknoticnucleiin cerebrum. In $5 \mathrm{ppm}$ treated group, cerebrum showed shrunken neurons with either pyknotic or karyorrhecticnuclei (Figure 7D). In both $10 \mathrm{mg} / \mathrm{kg}$ treated oral (Figure 8B) and intraperitoneal (Figure 8C) groups, cerebrum did not show any morphological alterations.

\subsubsection{Lungs}

There were no gross lesions observed in control group (Figure 9A). Among the inhalation groups, only the lungs of $5 \mathrm{ppm}$ treated group showed hemorrhages (Figure 9B). But no degeneration or necrotic changes were observed. Lungs of highest concentrated i.e. $10 \mathrm{mg} / \mathrm{kg}$ treatedoral (Figure 9C) and intraperitoneal (Figure 9D) groups did not show any morphological alterations.

\section{Discussion}

In the present study, gross and histomorphological studies have been carried out to investigate the changes in the dose dependent FA toxicity in brains and lungs of mice.

Among the inhalation, oral andintraperitoneal groups, in the present study there were no gross abnormalities observed after FA exposure. But in $5 \mathrm{ppm}$ treated inhalation group, the lungs were congested. This is due to the localization of FA toxicity and spreading of lesions with increasing exposure concentrations. Similar lesions in lungs following inhalation of FA has been reported in albino rats (Asmaa et al., 2012).

After acute FA inhalation, histomorphological examination revealed at high concentration i.e. $5 \mathrm{ppm}$ treated group marked hemorrhages in lungs but no degeneration or necrotic changes were observed whereas respiratory tract irritation, bronchioalveolar constriction and lung edema (WHO IPCS, 1989) were also observed. The severity of the lesions was reported to be dependent upon localization and cell type (Bhalla et al., 1991). High concentrations of FA cause marked hyperplasia and squamous metaplasia of the nasal respiratory epithelium. The lesions are primarily located in the anterior part of the nose and spread with increasing exposure time and concentrations to more distal locations in the nasal cavity (Monticello and Morgan, 1989; Kerns et al., 1983). The lesions developing in the nasal cavity at high concentrations increase in severity with prolonged exposure and depending on severity are not fully reversible even after considerable post exposure observation periods (Monticell and Morgan, 1994). The hazardous effects of FA on the respiratory epithelium (Roemer et al., 1993) 
may also account in the experimental animals. But Kerns et al. (1983) found no histomorphological changes in the lungs or in other organs in various chronic studies. This is due to high reactivity and the fast metabolic degradation in biological environments prevents its systemic availability via physiological exposure routes. It is revealed that inhaled FA is unlikely to be distributed systemically, due to a strong interaction and/or biotransformation occurring at the site of contact. So that exposure of animals (rats, nonhuman primates) to labelled exogenous FA resulted in the formation of labelled DNA and protein adducts at the site of contact (Edrissi et al., 2013; Moeller et al., 2011; Lu et al., 2010). That's why the localization of FA toxicity in the upper respiratory tract of rats and the absence of distant site toxicity are consistent with the high reactivity and rapid metabolism of inhaled FA. Distant site toxicity associated with FA exposure has not been observed in at least four inhalation bioassays of FA (Monticello and Morgan, 1989; Appelman et al., 1988; Woutersen et al., 1987; Sellakumar et al., 1985; Kerns et al., 1983). So there is no evidence of genuine systemic toxicity.

Since the half-life for FA elimination from the blood is about 1 min (McMartin et al., 1979) and because of its ability to pass through the blood-brain-barrier (Shcherbakova et al., 1986), it is suggested that small amounts of free FA could reach the nervous system and directly interact with the cells (Kilburn et al., 1987). In this study it has been shown that FA causes pyknosis and karyorrhecsis of nuclei of the nervous system (cerebrum).

Among the intraperitoneal groups noabnormal neuronal morphology was found but another researcher revealed, exposure to FA (10 mg/kg, 10 days) caused an increase in pyknosis and decreased neuronal number in the adult rat frontal cortex and hippocampus (Gurel et al., 2005). There are no histopathological changes observed on lungs after intraperitoneal injection to mice.

\section{Conclusions}

In conclusion, the present study revealed the increased mortality and lesions on the brain and lungs occurred mostly at highly FA exposed groups. This indicates that FA has adverse effects on neuronal morphology and also exerts respiratory toxicity. The toxic effects produced by FA become more pronounced with increasing in concentration and exposure duration.

\section{Acknowledgements}

This work was technically and financially supported by Department of Anatomy and Histology, Faculty of Veterinary Science, Bangladesh Agricultural University and Ministry of Science and Technology (Scholarship no. 66; June, 2014) of Bangladesh respectively.

\section{Conflict of interest}

None to declare.

\section{References}

Asmaa MT, M El-Ashtokhy, MA Hanan and YI Osama, 2012.Anatomical and Histological Effects of Formaldehyde Inhalation on the Lung of Albino Rat.J. Am. Sci., 8: 395-404

Appelman LM, RA Woutersen, AZwart, HE Falke and VJ Peron, 1988. One year inhalation toxicity study of Formaldehyde in male rats with a damaged or undamaged nasal mucosa.J. Appl. Toxicol., 8: 85-90.

Bancroft JD and A Gamble, 2002.Theory and practice of histological techniques. 5th ed., Churchill Livingstone, Newyork, London, pp. 165-180.

Bhalla DK, V Mahavni, T Nguyen and T McClure, 1991.Effects of acute exposure to Formaldehyde on surface morphology of nasal epithelia in rats. J. Toxicol. Environ. Health, 33: 171-188.

Cogliano V, Y Grosse, R Baan,K Straif, B Secretan, F Ghissassi and WHO, 2004.Advice on Formaldehyde and glycol ethers. Lancet Oncology, 5: 528.

Collins JJ and GA Lineker, 2004.A review and meta-analysis of Formaldehyde exposure and leukemia. Regul. Toxicol. Pharmacol., 40: 81-91.

Cui XL, L Lei, G Han, YP Li, YP Liu and YJ Wang, 1996. Distribution and influence to GSH of inhaled Formaldehyde in the rat. Chi. J. Prev. Med., 30: 186.

Edrissi B, K Taghizedeh and C Dedon, 2013. Quantitative Analysis of Histone Modifications: Formaldehyde is a Source of Pathological N6-Formyllysine that is Refractory to Histone Deacetylases. PLoS Genet., 9: 1-12.

Fujimaki H, Y Kurokawa, N Kunugita, M Kikuchi, F Sato and K Arashidani, 2004. Differential immunogenic and neurogenic inflammatory responses in an allergic mouse model exposed to low levels of Formaldehyde. Toxicology, 197: 1-13. 
Gurel A, O Coskun, F Armutcu, M Kanterand OA Ozen, 2005. Vitamin E against oxidative damage caused by Formaldehyde in frontal cortex and hippocampus: Biochemical and histological studies. J. Chem. Neuroanat., 29: 173-178.

Kerns WD, KL Pavkov, DJ Donofrio, EJ Gralla and JA Swenberg, 1983. Carcinogenicity of Formaldehyde in rats and mice after long term inhalation exposure. Cancer Res., 43: 4382-4392.

Kilburn KH, 1994.Neurobehavioral impairment and seizures from Formaldehyde.Arch. Environ. Occup.Health, 49: 37-44.

Kilburn KH, R Warshaw and JC Thornton, 1987. Formaldehyde impairs memory, equilibrium, and dexterity in histology technicians: Effects which persist for days after exposure. Arch. Environ. Occup.Health, 42: 117120.

Lu K, LB Collins, H Ru, E Bermudez and JA Swenberg, 2010. Distribution of DNA adducts caused by inhaled Formaldehyde is consistent with induction of nasal carcinoma but not leukemia. Toxicol. Sci., 116: 441-451.

McMartin KE, G Martin-Amat, PE Noker and TR Tephly, 1979.Lack of a role for Formaldehyde in methanol poisoning in the monkey. Biochem. Pharmacol., 28: 645-649.

Malek FA, KU Mörtiz and J Fanghanel, 2003. A study on specific behavioral effects of Formaldehyde in the rat. J. Exp. Anim. Sci., 42: 160-170.

Moeller BC, K Lu, M Doyle-Eisele, J McDonald, AGigliotti and JA Swenberg, 2011.Determination of N2hydroxymethyl-dG Adducts in Nasal Epithelium and Bone Marrow of Non-human Primates following 13CD2- Formaldehyde Inhalation Exposure.Chem. Res. Toxicol., 24: 162-164.

Monticello TM and KT Morgan, 1994.Cell proliferation and formaldehyde-induced respiratory carcinogenesis. Risk Anal., 14: 313-319.

Monticello TM and KT Morgan, 1989.Cell kinetics and characterization of "preneoplastic lesions in nasal respiratory epithelium of rats exposed to FA.American Association for Cancer Research.,30: Abstract 772.

Nakazawa H, H Ikeda, T Yamashita, I Hara, Y Kumai, G Endo andY Endo, 2005. A case of sick building syndrome in a Japanese office worker. Ind. Health., 43: 341-345.

National Institute of Health Guide for the Care and Use of laboratory Animals, 1985.DHEW Publication (NIH), revised, Office of Science and Health Reports, DRR/NIH, Bethesda, USA.

Nelson N, RJ Levine, RE Albert, 1986. Contribution of formaldehyde to respiratory cancer. Environ. Health Perspect., 70: 23-35.

Pitten FA, A Kramer, K Hermann, J Bremer and S Koch, 2000. Formaldehyde neurotoxicity in animal experiments.Pathol. Res.Pract., 196: 193-198.

Roemer E, HJ Anton and R Kindt, 1993. Cell proliferation in the respiratory tract of the rat after acute inhalation of Formaldehyde or acrolein. J. Appl.Toxicol., 13: 103-107.

Sellakumar AR,CA Snyder, JJ Solomon and RE Albert, 1985. Carcinogenicity of Formaldehyde and hydrogen chloride in rats.Toxicol. Appl. Pharmacol., 81: 401-406.

Shcherbakova LN, VI Tel'pukhov, SO Trenin, IA BashilovandTI Lapkina, 1986. Permeability of the bloodbrain barrier to intra-arterial Formaldehyde. Bull. Exp. Biol. Med., 102: 573-5.

Songur A, N Akpolat, I Kus, OA Ozen, I Zararsiz and M Sarsilmaz, 2003. The effects of the inhaled Formaldehyde during the early postnatal period in the hippocampus of rats: A morphological and immunohistochemical study. Neurosci. Res. Commun., 33: 168-178.

TOX Probe, 2002. Formaldehyde. Ten Carcinogens in Toronto, B-77-77.

WHO IPCS, 1989. Formaldehyde. Geneva, World Health Organization, International Programme on Chemical Safety. Environmental Health Criteria 89. pp. 219.

Woutersen RA, LM Appelman, JWGM Wilmer, HE Falke and VJ Feron, 1987. Subchronic (13-week) inhalation toxicity study of Formaldehyde in rats. J. Appl. Toxicol., 7: 43-49. 